\title{
Genetic Variation in Mouse Femoral Tissue-Level Mineral Content Underlies Differences in Whole Bone Mechanical Properties
}

\author{
Hayden-William Courtland ${ }^{a}$ Mila Spevak $^{b}$ Adele L. Boskey $^{b}$ Karl J. Jepsen ${ }^{a}$ \\ a Leni and Peter W. May Department of Orthopaedics, Mount Sinai School of Medicine, and ${ }^{\mathrm{b}}$ Musculoskeletal \\ Integrity Program, Hospital for Special Surgery, New York, N.Y., USA
}

\section{Key Words}

Bone fracture $\cdot$ Genetics $\cdot$ Mechanical properties $\cdot$ Tissue quality $\cdot$ Mouse

\begin{abstract}
A/J mice, as compared to C57BL/6J (B6) mice, have a significantly greater total femoral mineral (ash) content which correlates with an increased femoral stiffness (resistance to deformation), but also with an increased brittleness (catastrophic failure). To determine if this whole bone variation in mineral content is indicative of significant mineral and/or matrix variation at the tissue level, femora from 16-week-old female $A / J$ and $B 6$ mice were isolated, embedded in PMMA, sectioned and mounted on barium fluoride infrared windows for FTIRI analyses. In addition, preliminary studies of femora from $\mathrm{C} 3 \mathrm{H} / \mathrm{HeJ}(\mathrm{C} 3 \mathrm{H})$ mice were conducted, since they have an ash content intermediate to $\mathrm{A} / \mathrm{J}$ and $\mathrm{B} 6$. Mean values for mineral-to-matrix ratio were significantly different for $\mathrm{A} / \mathrm{J}(8.4 \pm 0.8)$ and $\mathrm{B} 6(7.5 \pm 0.4)$, as were values for collagen cross-link maturity $(1.8 \pm 0.05$ and $3.2 \pm 0.1$, respectively). $\mathrm{C} 3 \mathrm{H}$ mice appeared to have a mineral-to-matrix ratio intermediate of $A / J$ and $B 6$, and cross-link maturity greater than both $\mathrm{A} / \mathrm{J}$ and $\mathrm{B} 6$. B6 femora had similar carbonate-to-amide ratios, carbonate-to-mineral ratios and acid phosphate levels. Thus, whole bone differences in mineral content are concurrent with tissue-level variation in mineral
\end{abstract}

content and collagen maturity in inbred mice. The greater stiffness and brittleness of $\mathrm{A} / \mathrm{J}$ femora are likely due to differential biological control (osteoblast activity) of the amount of mineral.

Copyright $\odot 2008$ S. Karger AG, Basel

\section{Introduction}

Osteoporosis, a condition characterized by low bone mass and deterioration of bone microstructure, affects millions of people and costs the health care profession billions of dollars annually [Eddy et al., 1998]. Osteoporosis-induced skeletal fragility is an unusually complex pathology because the endpoint of disease (fracture) is a mechanical event. Both the morphology (size and shape) and quality (composition and tissue-level structure) of a bone determine its susceptibility to fracture. Although fracture susceptibility is known to be heritable, the genetic variation of bone compositional traits and the rela-

Abbreviations used in this paper
$\begin{array}{ll}\mathrm{B} 6 & \mathrm{C} 57 \mathrm{BL} / 6 \mathrm{~J} \\ \mathrm{C} 3 \mathrm{H} & \mathrm{C} 3 \mathrm{H} / \mathrm{HeJ}\end{array}$


Fig. 1. Representative FTIRI of mineralto-matrix ratio for $\mathrm{A} / \mathrm{J}, \mathrm{C} 3 \mathrm{H}$ and $\mathrm{B} 6$ femora. Regions shown represent an approximately $25-\mu \mathrm{m}$-tall portion of the anteriormedial quadrant of right femora from 16-week-old females. The color bar indicates increasing levels of mineral-to-matrix ratios from 2 to 8 .

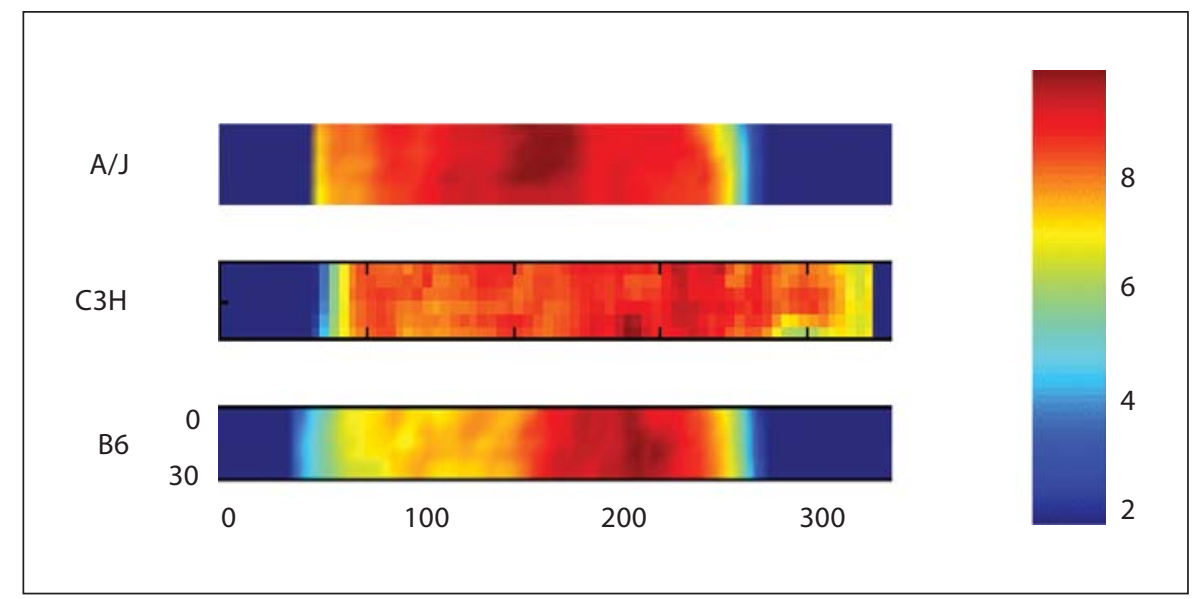

tionship between this variation and bone mechanical properties remains unclear.

Inbred mouse strains are a useful model for studying skeletal fragility because they have significant genetic homology to humans [Nadeau, 1989], and previous work has demonstrated that genes and gene products characterized in mice are of relevance in humans [Rizzoli et al., 2001]. In addition, inbred mice of a given strain are genetically identical, thereby minimizing the phenotypic variation among individuals and permitting trait comparisons among different cohorts. Research in our laboratory using 2 inbred strains of mice has demonstrated significant variation in whole bone mineral (ash) content and whole bone mechanical properties. Specifically, A/J mice have slender femora, which would tend to make them mechanically weaker than the larger femora of C57BL/6J (B6) mice [Price et al., 2005]. However, A/J mice have a greater total femoral ash content which correlates with an increased femoral stiffness (resistance to deformation), one that is comparable to that of B6 [Jepsen et al., 2001]. Interestingly, $\mathrm{C} 3 \mathrm{H} / \mathrm{HeJ}(\mathrm{C} 3 \mathrm{H})$ femora have a greater stiffness than both $\mathrm{A} / \mathrm{J}$ and $\mathrm{B} 6$ femora, even though they have an intermediate ash content. Thus, femora from inbred mice are able to achieve functionality for daily activity through varying combinations of morphological and compositional traits. What is not known is whether observed whole bone variation in mineral content is indicative of significant mineral and/or matrix variation at the tissue level. To determine if mouse femora with differing genetic backgrounds and whole bone mechanical properties will also exhibit tissue-level mineral and matrix variation, we analyzed $\mathrm{A} / \mathrm{J}, \mathrm{B} 6$ and $\mathrm{C} 3 \mathrm{H}$ femora using FTIR microspectroscopy.

\section{Materials and Methods}

Femora from 16-week-old female A/J, B6 and C3H mice were isolated, embedded in PMMA, sectioned (coronal, $2 \mu \mathrm{m}$ thick) and mounted on barium fluoride infrared windows for FTIRI analyses. Two to three replicate femoral sections were taken from each of 2-3 animals/strain (A/J and B6) and 1 animal/strain $(\mathrm{C} 3 \mathrm{H})$. Each section was analyzed using a Perkin Elmer Spotlight Imaging System. The spectral resolution was $4 \mathrm{~cm}^{-1}$ and regions of $25 \times$ $500 \mu \mathrm{m}$ were analyzed at approximately $7 \mu \mathrm{m}$ spatial resolution. Mineral-to-matrix area ratio $\left[\left(916-1,180 \mathrm{~cm}^{-1}\right) /\left(1,588-1,712 \mathrm{~cm}^{-1}\right)\right]$, carbonate-to-matrix area ratio $\left[\left(840-890 \mathrm{~cm}^{-1}\right) /(1,588-1,712\right.$ $\left.\left.\mathrm{cm}^{-1}\right)\right]$, carbonate-to-mineral area ratio $\left[\left(840-890 \mathrm{~cm}^{-1}\right) /(916-\right.$ $\left.\left.1,180 \mathrm{~cm}^{-1}\right)\right]$, collagen cross-linking $\left(1,660 / 1,690 \mathrm{~cm}^{-1}\right)$, crystallinity $\left(1,030 / 1,020 \mathrm{~cm}^{-1}\right)$ and acid phosphate $\left(1,106 / 960 \mathrm{~cm}^{-1}\right)$ parameters were calculated using ISYS Chemical Imaging Software. Significant differences in mean A/J and B6 FTIRI parameters were assessed using a t test with a significance threshold of $\mathrm{p}<0.05$.

\section{Results}

Mean mineral-to-matrix ratios for $\mathrm{A} / \mathrm{J}$ and $\mathrm{B} 6$ were 8.7 \pm 1.0 and $7.5 \pm 0.3$, respectively (fig. 1 ). Mean collagen cross-linking values were $1.8 \pm 0.05$ and $3.2 \pm 0.1$ for $\mathrm{A} / \mathrm{J}$ and B6, respectively. Both mineral-to-matrix and collagen cross-linking values were significantly different $(\mathrm{p}<0.05)$. A/J and B6 femora had similar carbonate-toamide ratios $(0.084 \pm 0.004$ and $0.075 \pm 0.008$, respectively) and carbonate-to-mineral ratios $(0.010 \pm 0.001$ and $0.009 \pm 0.001$, respectively), revealing no difference in the amount of carbonate-substituted mineral. Mineral crystallinity was also found to be similar between A/J $(1.18 \pm 0.03)$ and B6 $(1.19 \pm 0.04)$ as were values for acid phosphate $(6.4 \pm 0.9$ and $6.6 \pm 1.2$, respectively). Preliminary data from $\mathrm{C} 3 \mathrm{H}$ femora indicated a mineral-to- 


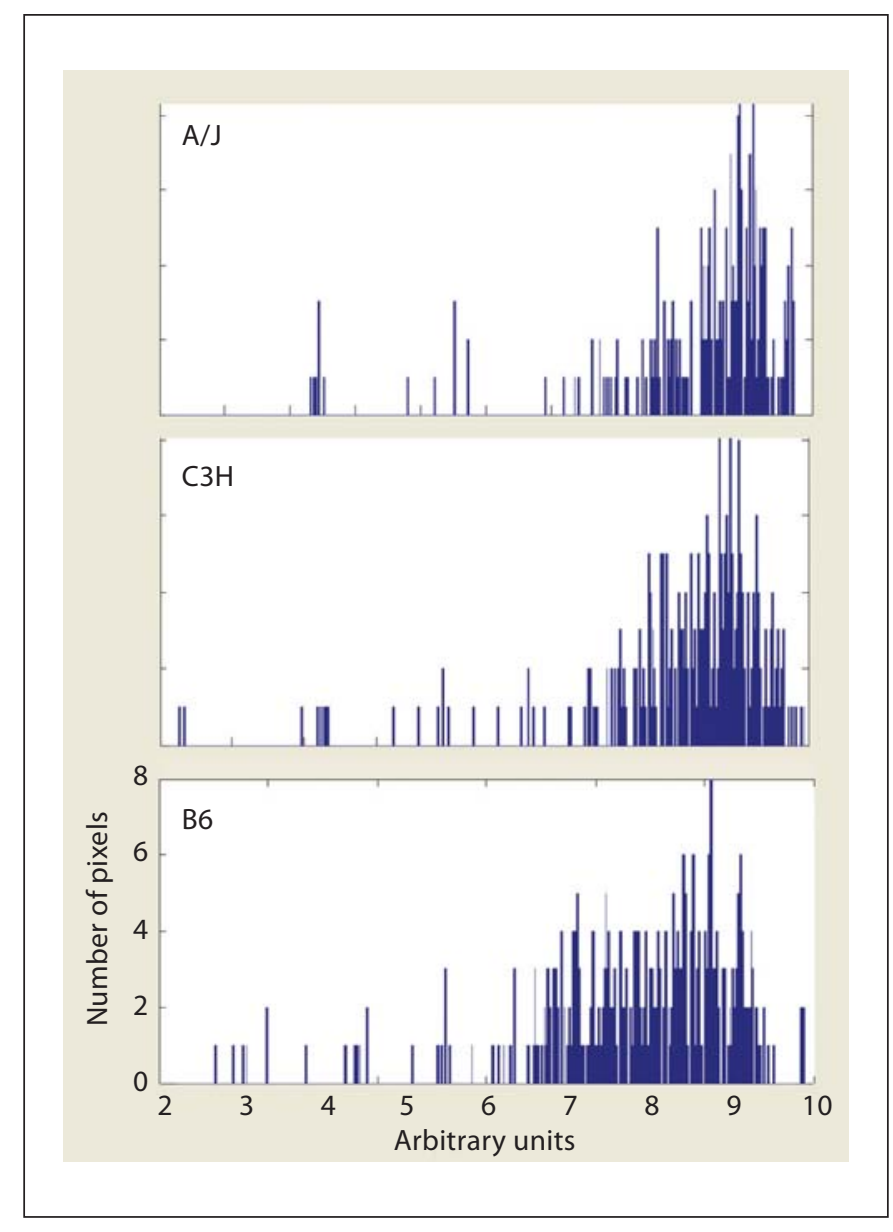

Fig. 2. Representative pixel population histograms of mineral-tomatrix ratios for $\mathrm{A} / \mathrm{J}, \mathrm{C} 3 \mathrm{H}$ and $\mathrm{B} 6$ femora. Data represent values from an approximately $25-\mu \mathrm{m}$-tall portion of the anterior-medial quadrant of right femora from 16 -week-old females.

matrix ratio that is intermediate to $\mathrm{A} / \mathrm{J}$ and $\mathrm{B} 6$ (fig. 1 ) and collagen cross-linking that is greater than both $A / J$ and B6. Preliminary data also suggested differences in carbonate substitution in $\mathrm{C} 3 \mathrm{H}$ femora compared to $\mathrm{A} / \mathrm{J}$ and B6. Although mean values of mineral-to-matrix were different among the 3 strains, mineral-to-matrix distribution did not appear to differ (fig. 2).

\section{Discussion}

The fact that no significant differences were found in carbonate-to-amide ratios and carbonate-to-mineral ratios between A/J and B6 femora indicates that carbonate substitution did not vary during growth or, if variations do exist during growth, that carbonate substitutions reached a common endpoint for these 2 strains by adulthood. A similar explanation can be applied to crystallinity and acid phosphate content, since neither parameter was significantly different between our 2 strains at 16 weeks of age. Although mineral composition did not vary between strains, the amount of mineral packed into the bone did. Specifically, results of this investigation demonstrated that differences in whole-bone ash content $(\mathrm{A} / \mathrm{J}>\mathrm{B} 6)$ are associated with significant tissue-level variation in mineral content. In addition, $\mathrm{C} 3 \mathrm{H}$ femora, with an ash content intermediate to $\mathrm{A} / \mathrm{J}$ and $\mathrm{B} 6$, were found to have an intermediate mineral-to-matrix ratio. These findings are in agreement with previous research which revealed a strong correlation between ash weight and spectroscopically determined mineral-to-matrix ratio in human biopsies [Faibish et al., 2005].

From an engineering perspective, A/J femora have a whole bone stiffness that is greater than expected based on their slender morphology and this has been attributed to a larger mineral (ash) content [Jepsen et al., 2001]. Here we show that mineral variation also exists at the tissue level and is likely a result of differential biological control (osteoblast activity) of the amount of mineral packed into the matrix. The increased mineral-to-matrix ratio of $\mathrm{A} / \mathrm{J}$ femora may impart a mechanical advantage at the tissue level, contributing to a larger than expected whole bone stiffness. However, given that increased mineral content is known to correlate with decreased post-yield behavior (increased brittleness) at the whole bone level, the increased tissue-level mineral content may similarly reduce tissue-level post-yield deformation.

Collagen cross-linking was found to be different among femora of $\mathrm{A} / \mathrm{J}, \mathrm{B} 6$ and $\mathrm{C} 3 \mathrm{H}$ mice. Compared to A/J femora, B6 femora were found to have more mature cross-links relative to immature cross-links. Although it is tempting to suggest that mature cross-links and tissuelevel mineral content may be inversely related, thereby imparting a mechanical advantage by increasing tissue stiffness, preliminary data from $\mathrm{C} 3 \mathrm{H}$ mice indicate that they have an intermediate tissue-level mineral content and yet more mature cross-links than both $\mathrm{A} / \mathrm{J}$ and $\mathrm{B} 6$ mice. Thus, how whole bone mechanical properties arise from tissue-level variation in mineral and collagen appears complex. It is currently unknown if greater collagen maturity in $\mathrm{B} 6$ and $\mathrm{C} 3 \mathrm{H}$ is a result of faster matrix maturation in these strains or greater tissue turnover in $\mathrm{A} / \mathrm{J}$. Longitudinal studies are necessary to determine if mineral-to-matrix ratio and collagen maturity differences between A/J, B6 and C3H exist throughout growth and 
development or if they manifest only at adulthood. In addition, future studies are necessary to determine if increases in mineral content and collagen maturity also contribute to increases in tissue-level mechanical properties such as stiffness and toughness.

\section{Acknowledgement}

Supported by grants from the NIH (AR44927, RR12305 and AR046121).

\section{References}

Eddy, D., C. Johnston, S. Cummings (1998) Os teoporosis: review of the evidence for prevention, diagnosis, and treatment and costeffectiveness analysis. Osteoporos Int 8: S1-S80.

Faibish, D., A. Gomes, G. Boivin, I. Binderman, A. Boskey (2005) Infrared imaging of calcified tissue in bone biopsies from adults with osteomalacia. Bone 36: 6-12.
Jepsen, K.J., D.E. Pennington, Y.L. Lee, M Warman, J. Nadeau (2001) Bone brittleness varies with genetic background in $\mathrm{A} / \mathrm{J}$ and C57BL/6J inbred mice. J Bone Miner Res 16 : 1854-1862.

Nadeau, J.H. (1989) Maps of linkage and synteny homologies between mouse and man. Trends Genet 5: 82-86.
Price, C., B.C. Herman, T. Lufkin, H.M. Goldman, K.J. Jepsen (2005) Genetic variation in bone growth patterns defines adult mouse bone fragility. J Bone Miner Res 20: 19831991.

Rizzoli, R., J.P. Bonjour, S.L. Ferrari (2001) Osteoporosis, genetics and hormones. J Mol Endocrinol 26: 79-94. 